Article

\title{
Five New Meroterpenoids from the Fruiting Bodies of the Basidiomycete Clitocybe clavipes with Cytotoxic Activity
}

\author{
Zhaocui Sun ${ }^{1}$, Xudong Xu ${ }^{1}$, Hanqiao Liang ${ }^{2}$, Xinyi Xia ${ }^{1}$, Guoxu Ma ${ }^{1, *}$ and Leiling Shi ${ }^{3, *}$ \\ 1 Key Laboratory of Bioactive Substances and Resource Utilization of Chinese Herbal Medicine, Ministry of \\ Education, Institute of Medicinal Plant Development, Peking Union Medical College and Chinese Academy \\ of Medical Sciences, Beijing 100193, China; flydancingsun@163.com (Z.S.); xdxu2012@163.com (X.X.); \\ xiaxinyi163@163.com (X.X.) \\ 2 Department of Biomedicine, Beijing City University, Beijing 100094, China; yaoxue2016@yeah.net \\ 3 Xinjiang Institute of Chinese and Ethnic Medicine, Urumqi 830002, China \\ * Correspondence: mgxfl8785@163.com (G.M.); shileiling@sina.com(L.S.)
}

Academic Editors: Luisa Tesoriere, Alessandro Attanzio, Rob Keyzers and René Csuk

Received: 21 September 2019; Accepted: 4 November 2019; Published: 6 November 2019

check for updates

\begin{abstract}
Five new meroterpenoids, clavipols A-B (1-2) with a 12-membered ether ring and clavilactones G-I (3-5) having a 10-membered carbocycle connected to a hydroquinone and an $\alpha, \beta$-epoxy/unsaturated lactone, were obtained from the fruiting bodies of the basidiomycete Clitocybe clavipes. Their structures were determined by comprehensive analysis of their spectroscopic data, and the absolute configuration of $\mathbf{1}$ was established by quantum chemical calculations of electronic circular dichroism (ECD). All the isolated compounds (1-5) were tested for their cytotoxic activity against three human tumor cell lines (Hela, SGC-7901, and SHG-44) in vitro after treatment for 48 h. Compound 4 exhibited moderate cytotoxic activity against Hela and SGC-7901 tumor cell lines, with $\mathrm{IC}_{50}$ values of 23.5 and $14.5 \mu \mathrm{M}$, respectively.
\end{abstract}

Keywords: meroterpenoids; Clitocybe clavipes; basidiomycete; cytotoxicity

\section{Introduction}

Secondary metabolites from fungi have attracted the attention of chemists, pharmacologists, and biologists because of their unique chemical structures and potential biological activities [1-3]. Meroterpenoids are defined as compounds partially derived from terpenoids [4]. In the past decades, fungal meroterpenoids, including pyripyropene A [5], arisugacins [6], and territrems [6], have been reported to have novel and fascinating chemical structures. They not only have diverse structural skeletons but also show biological activity, such as antitumor [7], anti-inflammatory [8], antioxidant [9], antibacterial [10], and antifungal [10] activities. Considering their unique structure and significant biological activities, total synthesis of fungal meroterpenoids has been achieved by synthetic chemists [11,12].

The fungus Clitocybe clavipes has rarely been chemically investigated. To the best of our knowledge, only 10 of its chemical constituents, 5 meroterpenoids, clavilactones A-E, and 5 fatty acid derivatives, have been isolated [13-15]. Moreover, the meroterpenoids clavilactones A-E have been reported to have potent pharmacological activity, such as antifungal activity and inhibition of protein tyrosine kinases [13,14]. Especially, clavilactone D was shown to inhibit epidermal growth factor receptor tyrosine kinase, with an $\mathrm{IC}_{50}$ value of $5.5 \mu \mathrm{M}$ [16]. Recently, we have reported the isolation of three novel meroterpenoids from the basidiomycete $C$. clavipes, clavipines $A-C$, possessing a benzoquinone fused to an azepine ring and a 10-membered carbocycle with $\alpha, \beta$-epoxy/unsaturated- $\gamma$-lactone. [17]. 
In our ongoing search for structurally unique and biologically valuable metabolites, an investigation of the extracts of the fruiting bodies of the basidiomycete $C$. clavipes led to the isolation of five new meroterpenoids, clavipols A-B (1-2) and clavilactones G-I (3-5) (Figure 1). This paper reports the isolation and structural elucidation of the five isolated new meroterpenoids, as well as their cytotoxic activities.<smiles>[R]Oc1ccc2cc1CC=C1C[C@H](O)C=C1CO2</smiles>

$1 \mathrm{R}=\mathrm{H}$

$2 \mathrm{R}=\mathrm{CH}_{3}$

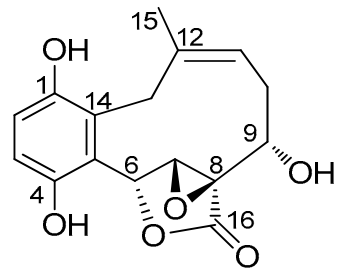

3<smiles>COc1ccc(O)c2c1C1=C[C@H](C/C(C)=C\CC2)C(=O)O1</smiles>

4<smiles></smiles>

5

Figure 1. Structures of compounds 1-5.

\section{Results}

Compound 1 was isolated as a colorless powder. Its molecular formula was established to be $\mathrm{C}_{16} \mathrm{H}_{20} \mathrm{O}_{3}$ on the basis of high-resolution electrospray ionization mass spectroscopy (HRESIMS) at $\mathrm{m} / \mathrm{z} 259.1329[\mathrm{M}-\mathrm{H}]^{-}$(calcd for 259.1340), indicating seven degrees of unsaturation. It had an IR absorption band at $3417 \mathrm{~cm}^{-1}$, which suggested the presence of hydroxyl groups. The ${ }^{1} \mathrm{H}-\mathrm{NMR}$ spectrum (Table 1, supplementary Figure S1) of 1 revealed the presence of one ABX aromatic system at $\left[\delta_{\mathrm{H}} 6.60(1 \mathrm{H}, \mathrm{d}, J=8.4 \mathrm{~Hz}, \mathrm{H}-3), 6.56(1 \mathrm{H}, \mathrm{dd}, J=3.0,8.4 \mathrm{~Hz}, \mathrm{H}-2), 7.23(1 \mathrm{H}, \mathrm{d}, J=3.0 \mathrm{~Hz}, \mathrm{H}-14)\right]$, three aliphatic methylenes $\left[\delta_{\mathrm{H}} 3.04(1 \mathrm{H}, \mathrm{dd}, J=7.2,16.8 \mathrm{~Hz}, \mathrm{H}-6 \mathrm{~b}), 3.34(1 \mathrm{H}, \mathrm{dd}, J=8.4,16.8 \mathrm{~Hz}\right.$, $\mathrm{H}-6 \mathrm{a}), 2.36(1 \mathrm{H}, \mathrm{t}, J=12 \mathrm{~Hz}, \mathrm{H}-9 \mathrm{~b}), 2.71(1 \mathrm{H}, \mathrm{dd}, J=4.2,12 \mathrm{~Hz}, \mathrm{H}-9 \mathrm{a}), 4.46(1 \mathrm{H}, \mathrm{d}, J=12.6 \mathrm{~Hz}, \mathrm{H}-13 \mathrm{~b})$, $4.64(1 \mathrm{H}, \mathrm{d}, J=12.6 \mathrm{~Hz}, \mathrm{H}-13 \mathrm{a})]$, two olefinic methines $\left[\delta_{\mathrm{H}} 5.74(1 \mathrm{H}, \mathrm{t}, J=7.2 \mathrm{~Hz}, \mathrm{H}-7), 5.56(1 \mathrm{H}, \mathrm{d}, J=\right.$ $10.2 \mathrm{~Hz}, \mathrm{H}-11)]$, one oxygenated methine $\left[\delta_{\mathrm{H}} 4.68(1 \mathrm{H}, \mathrm{m}, \mathrm{H}-10)\right]$, and two methyl groups $\left[\delta_{\mathrm{H}} 1.56(3 \mathrm{H}\right.$, $\left.\left.\mathrm{s}, \mathrm{H}_{3}-15\right), 1.24\left(3 \mathrm{H}, \mathrm{s}, \mathrm{H}_{3}-16\right)\right] .{ }^{13} \mathrm{C}-\mathrm{NMR}$ analysis with the aid of the HSQC spectra of 1 revealed 20 carbon signals composed of two methyls, three methylenes, five olefinic methines, five olefinic quaternary carbons, and one oxygenated methine. The proton signal at $\delta_{\mathrm{H}} 4.68(1 \mathrm{H}, \mathrm{m}, \mathrm{H}-10)$, together with the downfield methine carbon signal at $\delta_{\mathrm{C}} 66.0$, suggested the existence of a hydroxy group. Comprehensive analysis of 1D-NMR data indicated the existence of a 1,2,4-substituted hydrobenzene unit and the monoterpene moiety. 
Table 1. NMR spectral data of $\mathbf{1}$ and 2 (600 MHz for ${ }^{1} \mathrm{H}-\mathrm{NMR}$ and $150 \mathrm{MHz}$ for $\left.{ }^{13} \mathrm{C}-\mathrm{NMR}\right)$.

\begin{tabular}{|c|c|c|c|c|}
\hline \multirow[b]{2}{*}{ No. } & \multicolumn{2}{|l|}{1} & \multicolumn{2}{|l|}{2} \\
\hline & $\delta_{\mathrm{H}}(J$ in $\mathrm{Hz})$ & $\delta_{\mathrm{C}}$ & $\delta_{\mathrm{H}}(J$ in $\mathrm{Hz})$ & $\delta_{\mathrm{C}}$ \\
\hline 1 & - & 151.6 & - & 151.6 \\
\hline 2 & $6.56, \mathrm{dd}(3.0,8.4)$ & 115.3 & $6.64, \mathrm{dd}(3.0,8.4)$ & 114.7 \\
\hline 3 & $6.60, \mathrm{~d}(8.4)$ & 115.8 & $6.69, \mathrm{~d}(8.4)$ & 111.3 \\
\hline 4 & - & 147.1 & - & 151.4 \\
\hline 5 & - & 127.4 & - & 129.9 \\
\hline \multirow[t]{2}{*}{6} & $3.04, \mathrm{dd}(8.4,16.8), \mathrm{b}$ & 25.7 & $3.03, \mathrm{dd}(8.4,16.8), \mathrm{b}$ & 25.9 \\
\hline & $3.34, \mathrm{dd}(7.2,16.8), \mathrm{a}$ & & $3.39, \mathrm{dd}(7.2,16.8), \mathrm{a}$ & \\
\hline 7 & $5.74, \mathrm{t}(7.2)$ & 126.6 & $5.73, \mathrm{t}(7.2)$ & 127.2 \\
\hline 8 & - & 135.7 & - & 135.3 \\
\hline 9 & $\begin{array}{c}2.36, \mathrm{t}(12), \mathrm{b} \\
2.71, \mathrm{dd}(4.2,12), \mathrm{a}\end{array}$ & 48.6 & $\begin{array}{c}2.35, \mathrm{t}(12), \mathrm{b} \\
2.71, \mathrm{dd}(4.2,11.4), \mathrm{a}\end{array}$ & 48.7 \\
\hline 10 & $4.68, \mathrm{~m}$ & 66.0 & $4.68, \mathrm{~m}$ & 66.0 \\
\hline 11 & $5.56, \mathrm{~d}(10.2)$ & 135.4 & 5.57, d (10.2) & 135.3 \\
\hline 12 & - & 136.5 & - & 136.6 \\
\hline 13 & $\begin{array}{l}4.46, \mathrm{~d}(12.6), \mathrm{b} \\
4.64, \mathrm{~d}(12.6), \mathrm{a}\end{array}$ & 76.2 & $\begin{array}{l}4.47, \mathrm{~d}(12.6), \mathrm{b} \\
4.66, \mathrm{~d}(12.6), \mathrm{a}\end{array}$ & 76.2 \\
\hline 14 & $7.23, \mathrm{~d}(3.0)$ & 117.8 & $7.30, \mathrm{~d}(3.0)$ & 118.0 \\
\hline 15 & $1.56, \mathrm{~s}$ & 13.4 & $1.56, \mathrm{~s}$ & 13.4 \\
\hline 16 & $1.24, \mathrm{~s}$ & 16.1 & $1.23, \mathrm{~s}$ & 16.1 \\
\hline$-\mathrm{OCH}_{3}$ & - & - & $3.78, \mathrm{~s}$ & 56.1 \\
\hline
\end{tabular}

Spectra Data were Recorded in $\mathrm{CDCl}_{3}$

The ${ }^{1} \mathrm{H}_{-}{ }^{1} \mathrm{H}$ COSY spectrum (Figure 2) indicated the presence of two coupling fragments $\mathrm{H}-6 / \mathrm{H}-7$ and $\mathrm{H}-9 / \mathrm{H}-10 / \mathrm{H}-11$. A hydroxy group located at $\mathrm{C}-10$ in $\mathbf{1}$ was ascertained by the COSY correlations of $\mathrm{H}-10 / \mathrm{H}-11$ and $\mathrm{H}-10 / \mathrm{H}-9$, as well as by the HMBC correlations from $\mathrm{H}-10$ to $\mathrm{C}-9 / \mathrm{C}-11$. The HMBC correlations (Figure 2) from H-6 to C-4/C-5/C-7/C-14 established that the monoterpene was attached to C-5. Meanwhile, the HMBC correlations from H-9 to C-8/C-15 and from H-13 to C-11/C-12/C-13/C-15 indicated compound $\mathbf{1}$ was an ansa-type monoterpenylbenzenoid with a 12-membered ether ring [18]. The NMR data and biogenetical considerations indicated that the configuration of the two double bonds should be E. Finally, the planar structure of 1 was established, as shown in Figure 1, and the compound was given the name clavipol A.

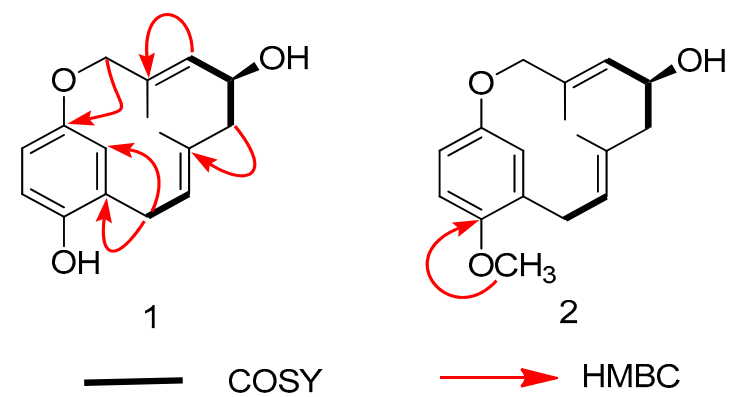

Figure 2. Key ${ }^{1} \mathrm{H}_{-}{ }^{1} \mathrm{H}$ COSY and HMBC correlations for compounds 1-2.

In the ROESY spectrum, correlations from $\mathrm{H}-10, \mathrm{H}-9 \mathrm{a}$, and $\mathrm{H}_{3}-15$ to $\mathrm{H}_{3}-16$ were observed (Figure 3), which allowed $\mathrm{H}-10$ to be placed on the same side of $\mathrm{H}_{3}-15$ and $\mathrm{H}_{3}-16$. In order to establish the absolute configuration of compound 1, density functional theory (DFT) calculations at the APFD/6-311+g (2d, p) level of the ECD spectra were carried out and compared with the experimental ones (Figure 4); their identical spectral profiles supported the $S$ configuration of C-10. 


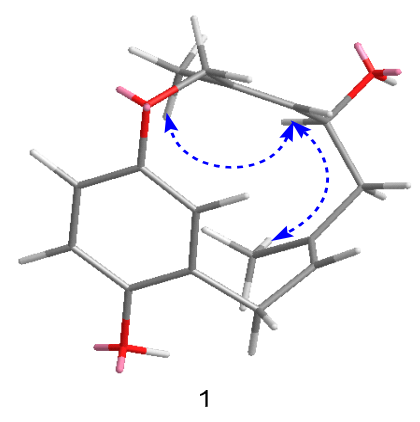

Figure 3. Key rotating overhauser effect correlations for compound $\mathbf{1 .}$
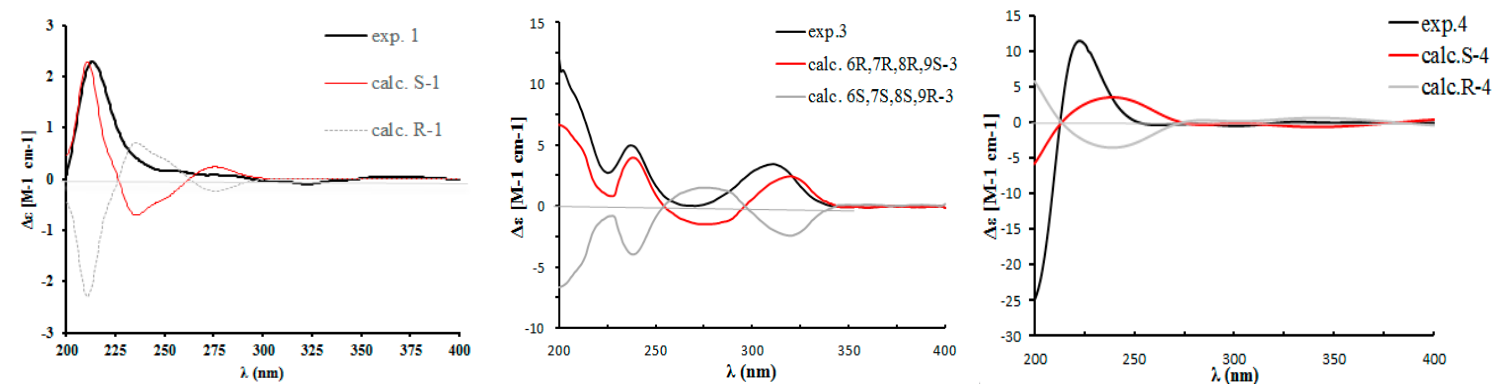

Figure 4. Calculated and experimental electronic circular dichroism (ECD) spectra of 1, 3, and 4 in methanol.

Compound 2 was obtained as a colorless powder with the molecular formula of $\mathrm{C}_{17} \mathrm{H}_{22} \mathrm{O}_{3}$ according to its negative ion HRESIMS peak at $\mathrm{m} / \mathrm{z} 273.1487[\mathrm{M}-\mathrm{H}]^{-}$(calcd 273.1496), indicative of 7 degrees of unsaturation and 14 more mass units with respect to 1 . The ${ }^{1} \mathrm{H}$ - and ${ }^{13} \mathrm{C}-\mathrm{NMR}$ spectroscopic data of compound $\mathbf{2}$ were quite similar to those of compound 1, except for an additional methoxy group $\left[\delta_{\mathrm{H}} 3.83(3 \mathrm{H}, \mathrm{s}) ; \delta_{\mathrm{C}} 56.1\right]$. In the HMBC spectrum, the methoxy signals had correlations with $\mathrm{C}-4$ $\left(\delta_{\mathrm{C}}\right.$ 151.4), indicating its connection to C-4 (Figure 2). Finally, the entire structure of compound 2 was elucidated as 4-methylated clavipol A. The absolute configuration of $\mathbf{2}$ was determined to be identical with that of $\mathbf{1}$ by comparing their ECD spectra (supplementary Figures S7 and S14), and the compound was given the name clavipol $\mathrm{B}$.

Compound 3 was isolated as a yellow powder, having the formula of $\mathrm{C}_{16} \mathrm{H}_{16} \mathrm{O}_{6}$ with nine degrees of unsaturation based on the HRESIMS at $m / z 303.0885[\mathrm{M}-\mathrm{H}]^{-}$(cal. 303.0874). Overall consideration of $1 \mathrm{D}-\mathrm{NMR}$ data (Table 2) suggested that compound 3 was a meroterpenoid similar to clavilactone A [13]. In detail, two aromatic protons at $\delta_{\mathrm{H}} 6.77(1 \mathrm{H}, \mathrm{d}, J=8.4 \mathrm{~Hz}, \mathrm{H}-2), 6.66(1 \mathrm{H}, \mathrm{d}, J=8.4 \mathrm{~Hz}, \mathrm{H}-3)$, together with six olefinic carbons at $\delta_{\mathrm{C}} 151.0$ (C-1), 118.9 (C-2), 115.7 (C-3), 151.0 (C-4), 120.8 (C-5), 128.1 (C-14), indicated the presence of one four-substituted benzene ring. ${ }^{13} \mathrm{C}$-APT NMR signals of $\delta_{\mathrm{C}} 77.1(\mathrm{C}-6), 64.7(\mathrm{C}-7), 62.8(\mathrm{C}-8)$, and 172.8 (C-16) indicated the presence of an $\alpha, \beta$-epoxy $\gamma$-lactone moiety, which was further confirmed by HMBC correlations from H-7 $(4.02$, s) to C-5, C-6, C-8, and C-16 (Figure 5). The methine signal at $\delta_{\mathrm{H}} 3.47(1 \mathrm{H}, \mathrm{dd}, J=3.0,12.0 \mathrm{~Hz})$ and $\delta_{\mathrm{C}} 71.3(\mathrm{C}-3)$ indicated that the hydroxyl group was substituted at $\mathrm{C}-9$, which was further supported by the HMBC correlations from $\delta_{\mathrm{H}} 3.47$ to $\mathrm{C}-8$ (62.8), C-10 (33.4), and C-16 (172.8). By analyzing the COSY spectrum, one proton-bearing structure fragment $\left[=\mathrm{CH}-\mathrm{CH}_{2}-\mathrm{CH}-\right]$ was readily established (indicated by bold bonds in Figure 2). In the HMBC spectrum, the correlations from H-13b to C-11, C-12, C-14, and C-15 and from H-9 to C-8, $\mathrm{C}-10$, and $\mathrm{C}-16$, indicated that compound 3 was a clavilactone homologue containing hydrobenzene fused to a 10-member carbocycle with $\alpha, \beta$-epoxy $\gamma$-lactone. As a result, compound 3 was established as 9-hydroxyl-substituted clavilactone $\mathrm{A}$. In the ${ }^{1} \mathrm{H}-\mathrm{NMR}$ spectrum, no vicinal coupling between the two adjacent protons H-6 and H-7 suggested these protons form a dihedral angle of approximately $90^{\circ}$, which means that the relative configurations of $C-6, C-7$, and $C-8$ are $6 R, 7 R, 8 R$ or $6 S, 7 S, 8 S$. In the NOESY spectrum, the correlations of $\mathrm{H}-7 \mathrm{a} / \mathrm{H}-9, \mathrm{H}-11, \mathrm{H}-13, \mathrm{H}_{3}-15$; H-9/H-11, H-7a, and H-10a/H-13b 
revealed the close proximity of these protons, and the observed correlation of $\mathrm{H}-9$ to $\mathrm{H}-7 \mathrm{a}$ and $\mathrm{H}-11$ (Figure 6) allowed H-9 to be placed on the side H-9b due to the reported correlations between $\mathrm{H}-9 \mathrm{~b}$ to $\mathrm{H}-7 \mathrm{a}$ in clavilactone A $[13,17]$. The positive cotton effects at 237 and $308 \mathrm{~nm}$ showed in the ECD spectrum of 3 (supplementary Figure S21) were in good agreement with the calculated CD spectrum of $6 R, 7 R, 8 R, 9 S$ configuration for 3, as shown in Figure 4. Thus, the absolute configuration of 3 was determined to be $6 R, 7 R, 8 R, 9 S$, and the compound was given the name clavilactone $G$.

Table 2. NMR spectral data of 3-5 (600 MHz for ${ }^{1} \mathrm{H}-\mathrm{NMR}$ and $150 \mathrm{MHz}$ for $\left.{ }^{13} \mathrm{C}-\mathrm{NMR}\right)$.

\begin{tabular}{|c|c|c|c|c|c|c|}
\hline \multirow[b]{2}{*}{ No. } & \multicolumn{2}{|l|}{$3^{a}$} & \multicolumn{2}{|l|}{$4^{b}$} & \multicolumn{2}{|l|}{$5^{b}$} \\
\hline & $\delta_{\mathrm{H}}(J$ in $\mathrm{Hz})$ & $\delta_{\mathrm{C}}$ & $\delta_{\mathrm{H}}(J$ in $\mathrm{Hz})$ & $\delta_{\mathrm{C}}$ & $\delta_{\mathrm{H},}(J$ in $\mathrm{Hz})$ & $\delta_{\mathrm{C}}$ \\
\hline 1 & - & 151.0 & - & 149.1 & - & 148.9 \\
\hline 2 & $6.77, \mathrm{~d}(8.4)$ & 118.9 & $6.79, \mathrm{~d}(8.4)$ & 117.2 & $6.83, \mathrm{~d}(9.0)$ & 117.5 \\
\hline 3 & 6.66, d (8.4) & 115.7 & $6.75, \mathrm{~d}(8.4)$ & 111.1 & $6.75, \mathrm{~d}(9.0)$ & 110.8 \\
\hline 4 & - & 151.0 & - & 153.1 & - & 153.1 \\
\hline 5 & - & 120.8 & - & 120.5 & - & 122.4 \\
\hline 6 & $6.30, \mathrm{~s}$ & 77.1 & $6.84, \mathrm{~s}$ & 76.1 & $6.37, \mathrm{~s}$ & 74.6 \\
\hline 7 & $4.02, \mathrm{~s}$ & 64.7 & $6.80, \mathrm{~s}$ & 149.7 & $4.01, \mathrm{~s}$ & 63.8 \\
\hline 8 & - & 62.8 & - & 129.2 & - & 61.8 \\
\hline 9 & $\begin{array}{c}3.47, \mathrm{dd} \\
(3.0,12.0), \mathrm{m}\end{array}$ & 71.3 & $\begin{array}{l}1.87, \mathrm{~m}, \mathrm{~b} \\
2.74, \mathrm{~m}, \mathrm{a}\end{array}$ & 25.6 & $\begin{array}{l}1.27, \mathrm{~m}, \mathrm{~b} \\
2.73, \mathrm{~m}, \mathrm{a}\end{array}$ & 25.3 \\
\hline 10 & $\begin{array}{l}2.27, \mathrm{~m}, \mathrm{~b} \\
2.85, \mathrm{~m}, \mathrm{a}\end{array}$ & 33.4 & $\begin{array}{l}1.97, \mathrm{~m}, \mathrm{~b} \\
2.23, \mathrm{~m}, \mathrm{a}\end{array}$ & 24.9 & $\begin{array}{l}2.18, \mathrm{~m}, \mathrm{~b} \\
2.48, \mathrm{~m}, \mathrm{a}\end{array}$ & 22.7 \\
\hline 11 & $5.27, \mathrm{t}(7.8)$ & 119.8 & $5.12, \mathrm{t}(7.8)$ & 121.4 & $5.27, \mathrm{t}(8.4)$ & 122.4 \\
\hline 12 & - & 141.7 & - & 140.1 & - & 137.8 \\
\hline 13 & $\begin{array}{l}3.02, \mathrm{~d}(15.6), \mathrm{b} \\
3.69, \mathrm{~d}(15.6), \mathrm{a}\end{array}$ & 28.5 & $\begin{array}{l}2.58, d(15.0), b \\
3.32, d(15.0), a\end{array}$ & 27.0 & $\begin{array}{c}3.09, \mathrm{~d}(15.6), \mathrm{b} \\
3.693, \mathrm{~d}(15.6) \\
\mathrm{a}\end{array}$ & 27.9 \\
\hline 14 & - & 128.1 & - & 128.0 & - & 128.4 \\
\hline 15 & $1.56, \mathrm{~s}$ & 22.1 & $1.59, \mathrm{~s}$ & 22.1 & $1.56, \mathrm{~s}$ & 21.6 \\
\hline 16 & - & 172.8 & - & 175.2 & - & 172.8 \\
\hline$-\mathrm{OCH}_{3}$ & - & - & $3.83, \mathrm{~s}$ & 57.1 & $3.80, \mathrm{~s}$ & 56.8 \\
\hline
\end{tabular}

${ }^{\mathrm{a}}$ Spectral data were recorded in $\mathrm{CD}_{3} \mathrm{OD} ;{ }^{\mathrm{b}}$ Spectral data were recorded in $\mathrm{CDCl}_{3}$.

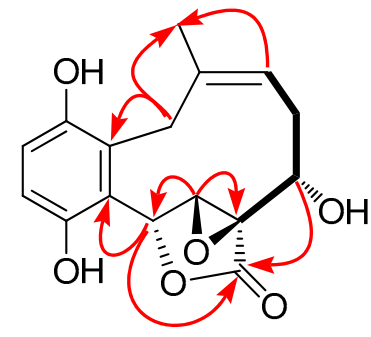

3

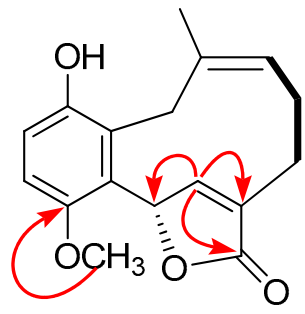

4

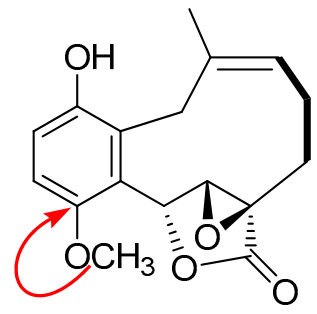

5

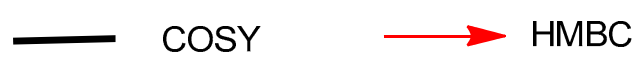

Figure 5. Key ${ }^{1} \mathrm{H}_{-}{ }^{1} \mathrm{H}$ COSY and HMBC correlations for compounds 3-5.

Compound 4 was isolated as a yellow powder. The HRESIMS displayed an $[\mathrm{M}-\mathrm{H}]^{-}$ion peak at $m / z 285.1132$ (calcd 285.1132), which showed the molecular formula $\mathrm{C}_{17} \mathrm{H}_{18} \mathrm{O}_{4}$. The IR spectrum suggested the presence of hydroxyl $\left(3370 \mathrm{~cm}^{-1}\right)$ and carbonyl groups $\left(1714 \mathrm{~cm}^{-1}\right)$. By intensive comparison of the ${ }^{1} \mathrm{H}$ and ${ }^{13} \mathrm{C}-\mathrm{NMR}$ data (Table 2) with those of clavilactone $\mathrm{A}$, significant differences were the absence of two oxygenated carbon signals and the presence of a double bond $\left[\delta_{\mathrm{H}} 6.80(1 \mathrm{H}, \mathrm{s})\right.$; $\left.\delta_{\mathrm{C}} 149.7,129.2\right]$ as well as of a methoxy group $\left[\delta_{\mathrm{H}} 3.83(3 \mathrm{H}, \mathrm{s}) ; \delta_{\mathrm{C}} 53.1\right]$ in 4 . In the HMBC spectrum, the correlations from $\delta_{\mathrm{H}} 6.80$ to C-6, C-8, and C-16 established that the $\alpha, \beta$-epoxy- $\gamma$-lactone moiety in clavilactone $\mathrm{A}$ had been cracked and dehydrated to form an $\alpha, \beta$-unsaturated- $\gamma$-lactone unit in 4 . 
The methoxy group was attached to $\mathrm{C}-4$ on the basis of the HMBC correlation from protons $\left(\delta_{\mathrm{H}} 3.83\right)$ to $C-4\left(\delta_{C} 153.1\right)$. The experimental ECD spectrum of 4 exhibited the positive cotton effect at $222 \mathrm{~nm}$ (supplementary Figure S28), in agreement with the calculated CD spectrum of $6 S$ configuration for 4 (Figure 4). Thus, the absolute configuration of 4 was determined as $S$, and the compound was given the name clavilactone $\mathrm{H}$.

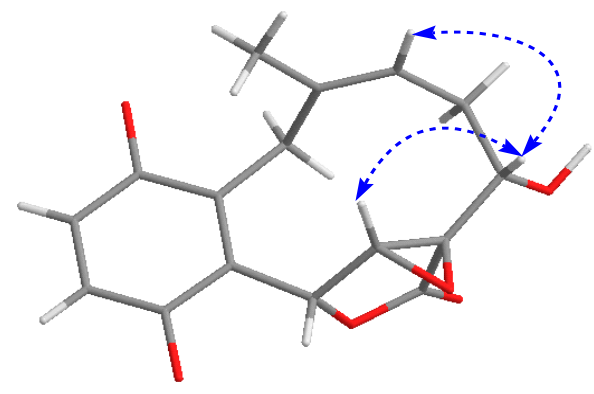

3

Figure 6. Key nuclear overhauser effect (NOE) correlations for compound 3.

Compound 5 was isolated as a yellow amorphous powder. The HRESIMS displayed an $[\mathrm{M}-\mathrm{H}]^{-}$ ion peak at $m / z 301.1070[\mathrm{M}-\mathrm{H}]^{-}$(calcd 301.1081), which showed the molecular formula $\mathrm{C}_{17} \mathrm{H}_{18} \mathrm{O}_{5}$ and 14 more mass units than clavilactone A [13]. Its IR bands at $3436 \mathrm{~cm}^{-1}$ and $1749 \mathrm{~cm}^{-1}$ suggested the existence of hydroxyl and carbonyl groups. Overall consideration of ${ }^{1} \mathrm{H}$ and ${ }^{13} \mathrm{C}$ data of 5 indicated compound 5 could be a methylation derivative of clavilactone A, which was further supported by its $\mathrm{HMBC}$ spectrum. In the HMBC spectrum, the correlation between $\delta_{\mathrm{H}}(3.83, \mathrm{~s})$ and $\mathrm{C}-4\left(\delta_{\mathrm{C}} 153.1\right)$ established the presence of a methoxy group $\left(\delta_{C} 57.1\right)$ attaching to C-4 in compound 5 (Figure 5). Considering the identical CD spectra of compound 5 and clavilactone A (supplementary Figures S34 and S35), compound 5 should have the same absolute configuration of calvilactone A, and was given the name clavilactone I.

Furthermore, all isolated compounds (1-5) were evaluated for their cytotoxicity against three human tumor cell lines (Hela, SGC-7901, and SHG-44) in vitro by treatment for $48 \mathrm{~h}$, using the MTT assay [19]; cisplatin was used as the positive control drug. The results of cytotoxicity are displayed in Table 3. Compound 4 exhibited moderate cytotoxic activity against Hela and SGC-7901 tumor cell lines, with $\mathrm{IC}_{50}$ values of 23.5 and $14.5 \mu \mathrm{M}$, respectively.

Table 3. In vitro cytotoxic activity of compounds $\mathbf{1 - 5}$.

\begin{tabular}{cccc}
\hline \multirow{2}{*}{ Compounds } & \multicolumn{3}{c}{ IC $_{50}(\mu \mathrm{M})$} \\
\cline { 2 - 4 } & Hela & SGC-7901 & SHG-44 \\
\hline 1 & $63.2 \pm 0.43^{\text {a }}$ & $44.1 \pm 0.5$ & $>100$ \\
2 & $38.6 \pm 1.3$ & $51.2 \pm 0.7$ & $>100$ \\
3 & $>100$ & $62.2 \pm 0.4$ & $>100$ \\
4 & $23.5 \pm 0.4$ & $14.5 \pm 1.2$ & $53.9 \pm 2.4$ \\
5 & $>100$ & $84.2 \pm 3.1$ & $>100$ \\
Cisplatin & $2.7 \pm 0.04$ & $1.1 \pm 0.05$ & $1.8 \pm 0.03$ \\
\hline a The values presented are the means \pm SD of triplicate experiments.
\end{tabular}

\section{Discussion}

The chemical investigation of the fungus $C$. clavipes led to the isolation of five new meroterpenoids, clavipols A-B (1-2) with a 12-membered ether ring and clavilactones G-I (3-5) having a 10-membered carbocycle connected to a hydroquinone and an $\alpha, \beta$-epoxy/unsaturated lactone. This study contributes to broadening the list of known chemically diverse meroterpenoids from the fungus C. clavipes. 
Until now, only about 20 naturally occurring meroterpenoids with a benzo-fused 10-membered carbocycle unit have been isolated from plants and fungi [17]. These meroterpenoids have been shown to display potent cytotoxic activities [20]. For example, terreumols A, isolated from the mushroom Tricholoma terreum, displayed potent cytotoxic activity against A-549 cancer cell line, with an $\mathrm{IC}_{50}$ value of $4.2 \mu \mathrm{M}$ [20]. Compared with the cytotoxic activities of compounds 3 and 5, compound 4 exhibited moderate cytotoxic activity against Hela and SGC-7901 cancer cell lines, with IC $_{50}$ values of 23.5 and $14.5 \mu \mathrm{M}$, respectively. Therefore, we speculate that different degrees of oxidation of such compounds may affect their cytotoxic activities.

\section{Materials and Methods}

\subsection{General Experimental Procedures}

1D and 2D-NMR spectra were obtained with a Bruker AV 600 NMR spectrometer (chemical shift are presented as $\delta$ values with TMS as the internal standard) (Bruker, Billerica, Germany). HRESIMS was performed on a Q-tof spectrometer (Waters, Milford, MA, USA). UV and IR data were obtained using a Shimadzu UV2550 spectrophotometer and a FTIR-8400S spectrometer (Shimadzu, Kyoto, Japan), respectively. CD spectra were obtained using a JASCO J-815 spectropolarimeter (Tokyo, Japan). Thin-layer chromatography (TLC) was performed on pre-coated silica gel GF254 (Zhi Fu Huang Wu Pilot Plant of Silica Gel Development, Yantai, China). Semi-preparative HPLC was conducted on an analytic LC equipped with a pump of P230 and a DAD detector of 230+ (Ellte, Dalian, China) with a $\mathrm{C}_{18}$ ODS-A (5 $\mu \mathrm{m}, \mathrm{YMC}$, Kyoto, Japan). Column chromatography used silica gel columns (200-300 mesh, Qingdao Marine Chemical plant, Qingdao, China). All solvents used were of analytical grade (Beijing Chemical Plant, China).

\subsection{Computational Methods}

The ECD calculations were carried out using Gaussian 09 program (Inc., WALLINGFORD, CT, USA). Conformers were generated by MMFF94s force field, each conformer was optimized with the HF/6-31G(d) method, and further optimized with the DFT method at the B3LYP/6-311+g(d, p) level. Frequency calculations were also performed at the same level to confirm that each optimized conformer was true minimum and to estimate their relative thermal free energy $(\Delta \mathrm{G})$ at $298.15 \mathrm{~K}$. Conformers with the Boltzmann distribution over $1 \%$ were chosen for ECD calculations in methanol at the APFD/6-311+g(2d, p) level. The ECD spectra were simulated by the SpecDis program. To obtain the final conformationally averaged data, the simulated spectra of the predominant conformers were averaged according to the Boltzmann distribution theory.

\subsection{Fungal Material}

The fruiting bodies of Clitocybe clavipes were collected from Hotan Prefecture, Xinjiang Uygur Autonomous Region, China, in July 2018. The fungus was identified by Prof. Leiling Shi, Xinjiang Institute of Chinese and Ethnic Medicine, where a voucher specimen of C. clavipes (No. 201812) was preserved.

\subsection{Extraction and Isolation}

The dried fruiting bodies of $C$. clavipes $(0.6 \mathrm{~kg})$ were macerated three times with EtoAc. The solvents were filtrated and evaporated in vacuum to give the total extract $(45 \mathrm{~g})$, and this residue was subjected to silica-gel (200-300 mesh) column chromatography (CC) with two gradient systems (ether/EtOAc 30:1, 10:1, 5:1,1:1; $\left.\mathrm{CH}_{2} \mathrm{Cl}_{2} / \mathrm{MeOH} 20: 1,10: 1,5: 1,1: 1, v / v\right)$ to give 8 fractions (F1-F8). F3 was purified by semi-preparative HPLC $\left(\mathrm{CH}_{3} \mathrm{CN} / \mathrm{H}_{2} \mathrm{O} 60: 49, v / v\right)$ to yield $1\left(3 \mathrm{mg}, t_{\mathrm{R}}=15.5 \mathrm{~min}\right)$ and $2(2 \mathrm{mg}$, $\left.t_{\mathrm{R}}=17.1 \mathrm{~min}\right)$. F4-5 were subjected to $\mathrm{C}-18$ reversed-phase (RP) silica-gel CC using $\mathrm{MeOH} / \mathrm{H}_{2} \mathrm{O}$ in a linear gradient (30:70, 45:55, 60:40, 80:20, 100:0, v/v) to obtain 5 fractions (F4-5.a-F4-5.e). F4-5.d was 
purified by semi-preparative HPLC with $\mathrm{CH}_{3} \mathrm{CN}-\mathrm{H}_{2} \mathrm{O}$ as mobile phase $(45: 55, v / v)$, to give 3 ( $2 \mathrm{mg}$, $\left.t_{\mathrm{R}}=12.4 \mathrm{~min}\right), 4\left(2 \mathrm{mg}, t_{\mathrm{R}}=20.0 \mathrm{~min}\right)$, and $5\left(3 \mathrm{mg}, t_{\mathrm{R}}=22.1 \mathrm{~min}\right)$.

The structures of compounds $\mathbf{1 - 5}$ were determined by HRESIMS, UV, IR, 1D and 2D-NMR spectra.

Clavipol A (1), colorless powder; $[\alpha]^{25} \mathrm{D}+18.6$ (c $\left.0.11, \mathrm{MeOH}\right)$; UV(MeOH) $\lambda_{\max }(\log \varepsilon) 204(3.54)$, 291(3.2) nm; IR(KBr) $v_{\max } 3417,2917,2851,1596,1385,1118,768,544 \mathrm{~cm}^{-1} ;{ }^{1} \mathrm{H}$ and ${ }^{13} \mathrm{C}-\mathrm{NMR}$ data see Table 1; (-)HRESIMS $m / z$ 259.1329 [M - H] ${ }^{-}$(calcd for 259.1340).

Clavipol B (2), colorless powder; $[\alpha]^{25} \mathrm{D}+18.0$ (c 0.10, $\left.\mathrm{MeOH}\right) ; \mathrm{UV}(\mathrm{MeOH}) \lambda_{\max }(\log \varepsilon) 203(3.3)$, 290(3.1) nm; IR(KBr) $v_{\max } 3418,2914,2849,1593,1383,1115,763,546 \mathrm{~cm}^{-1} ;{ }^{1} \mathrm{H}$ and ${ }^{13} \mathrm{C}$ NMR data see Table 1; (-)HRESIMS $m / z 273.1487$ [M - H] ${ }^{-}$(calcd 273.1496).

Clavilactone G (3), yellow powder; $[\alpha]^{25} \mathrm{D}+50.8(\mathrm{c} 0.10, \mathrm{MeOH}) ; \mathrm{UV}(\mathrm{MeOH}) \lambda_{\max }(\log \varepsilon) 235(3.91)$, 310(3.52) nm; IR(KBr) $v_{\max } 3440,2944,1776,1487,1419,1233,1210,802 \mathrm{~cm}^{-1} ;{ }^{1} \mathrm{H}$ and ${ }^{13} \mathrm{C}-\mathrm{NMR}$ data see Table 2; (-)HRESIMS m/z 303.0885 [M - H] $]^{-}$(cal. 303.0874).

Clavilactone $\mathrm{H}(4)$, yellow powder; $[\alpha]^{25}{ }_{\mathrm{D}}-21.8$ (c 0.06, MeOH); $\mathrm{UV}(\mathrm{MeOH}) \lambda \max (\log \varepsilon) 209(3.91)$, 281(3.52) nm; IR(KBr) $v_{\max } 3370,2925,2853,1743,1599,1453,1267,1076,807 \mathrm{~cm}^{-1} ;{ }^{1} \mathrm{H}$ and ${ }^{13} \mathrm{C} N M R$ data see Table 2; (+)HRESIMS $m / z$ 285.1132(calcd 285.1132).

Clavilactone I (5), yellow powder; $[\alpha]^{25} \mathrm{D}+90.5$ (c 0.12, MeOH); UV(MeOH) $\lambda \max (\log \varepsilon) 236(3.70)$, 310(3.56) $\mathrm{nm}$; IR(KBr) $\mathrm{v}_{\max } 3435,2930,1749,1487,1260,1152,1021,800 \mathrm{~cm}^{-1} ;{ }^{1} \mathrm{H}$ and ${ }^{13} \mathrm{C}$ NMR data see Table 2; (-)HRESIMS m/z $301.1070\left[\mathrm{M}-\mathrm{H}^{-}\right.$(calcd 301.1081).

\subsection{Cytotoxicity Assays}

Compounds 1-5 were evaluated for their cytotoxic activity by the MTT method using Hela, SGC-7901, and SHG-44 cancer cell lines. Cells were grown in DMEM medium and cultured at a density of $6 \times 10^{4}$ cells $/ \mathrm{mL}$ per well in a 96-well microtiter plate. Then, different concentrations of the isolated compounds dissolved in dimethyl sulfoxide (DMSO) were added to each well. Each concentration was tested in triplicate. After incubation at $37^{\circ} \mathrm{C}$ in $5 \% \mathrm{CO}_{2}$ for $48 \mathrm{~h}, 10 \mu \mathrm{L}$ of MTT was added to each well, and incubation was continued for additional $4 \mathrm{~h}$. Then, the liquid was removed from the wells and DMSO was added to each well. The absorbance was recorded on a microplate reader at a wavelength of $570 \mathrm{~nm}$.

Supplementary Materials: Supplementary Materials are available online.

Author Contributions: G.M. and L.S. conceived and designed the experiments; Z.S. wrote the paper and performed the experiments; X.X. (Xudong Xu) helped during the structural elucidation; H.L. and X.X. (Xinyi Xia) assisted in the collating of NMR data.

Funding: The work was financially supported by the CAMS Innovation Fund for Medical Sciences (CIFMS) (No. 2017-I2M-1-013) and the National Natural Sciences Foundation of China (No. 81502945).

Conflicts of Interest: The authors have declared no conflict of interest.

\section{Abbreviations}

The following abbreviations are used in this manuscript:

IR Infrared

NMR Nuclear magnetic resonance

HR-ESI-MS High resolution electrospray ionization mass spectroscopy

HMBC Heteronuclear multiple bond correlation

HSQC Heteronuclear single quantum correlation

COSY Homonuclear chemical shift Correlation Spectroscopy

NOESY Nuclear overhauser effect spectroscopy

ROESY Rotating frame overhauser effect spectroscopy

APFD Austin-Frisch-Petersson functional with dispersion

TMS Tetramethylsilane 


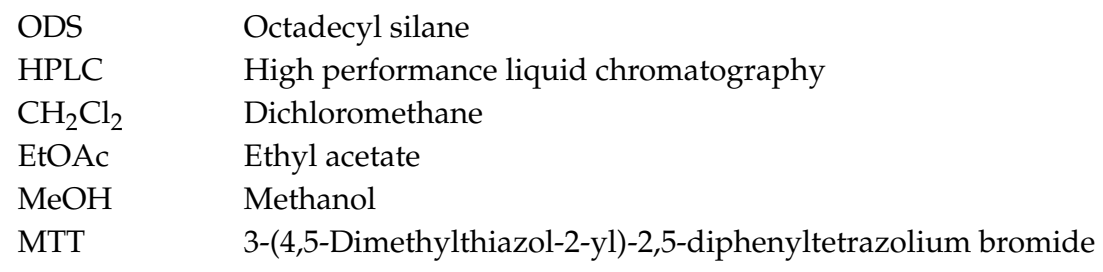

\section{References}

1. Niu, Z.; Chen, Y.; Guo, H.; Li, S.N.; Li, H.H.; Liu, H.X.; Liu, Z.; Zhang, W. Cytotoxic Polyketides from a Deep-Sea Sediment Derived Fungus Diaporthe phaseolorum FS431. Molecules 2019, 24, 3062. [CrossRef] [PubMed]

2. Verma, V.C.; Kharwar, R.N.; Strobel, G.A. Chemical and functional diversity of natural products from plant associated endophytic fungi. Nat. Prod. Commun. 2009, 4, 1511-1532. [CrossRef] [PubMed]

3. Tang, Y.; Xue, Y.; Du, G.; Wang, J.; Liu, J.; Sun, B.; Li, X.N.; Yao, G.; Luo, Z.; Zhang, Y. Structural revisions of a class of natural products: Scaffolds of aglycon analogues of fusicoccins and cotylenins isolated from fungi. Angew. Chem. Int. Ed. 2016, 128, 4137-4141. [CrossRef]

4. Geris, R.; Simpson, T.J. Meroterpenoids produced by fungi. Nat. Prod. Rep. 2009, 26, 1063. [CrossRef] [PubMed]

5. Tomoda, H.; Nishida, H.; Kim, Y.K.; Obata, R.; Sunazuka, T.; Omura, S. Relative and absolute stereochemistry of pyripyropene A, a potent, bioavailable inhibitor of Acyl-CoA:Cholesterol Acyltransferase (ACAT). J. Am. Chem. Soc. 1994, 116, 12097-12098. [CrossRef]

6. Kuno, F.; Shiomi, K.; Otoguro, K.; Sunazuka, T.; Omura, S. Arisugacins A and B, novel and selective acetylcholinesterase inhibitors from penicillium sp. F0-4259. II. structure elucidation. J. Antibiot. 1996, 49, 748-751. [CrossRef] [PubMed]

7. He, Y.; Zheng, M.; Li, Q.; Hu, Z.; Zhu, H.; Liu, J.; Wang, J.; Xue, Y.; Li, H.; Zhang, Y. Asperspiropene A, a novel fungal metabolite as an inhibitor of cancer-associated mutant isocitrate dehydrogenase 1. Org. Chem. Front. 2017. [CrossRef]

8. Liu, Z.; Liu, H.; Chen, Y.; She, Z. A new anti-inflammatory meroterpenoid from the fungus Aspergillus terreus H010. Nat. Prod. Res. 2017, 32, 1-5. [CrossRef] [PubMed]

9. Peng, X.; Li, L.; Wang, X.; Zhu, G.; Li, Z.; Qiu, M. Antioxidant farnesylated hydroquinones from Ganoderma capense. Fitoterapia 2016, 111, 18-23. [CrossRef] [PubMed]

10. Xu, L.; Meng, W.; Cao, C.; Wang, J.; Shan, W.; Wang, Q. Antibacterial and antifungal compounds from marine fungi. Mari. Drugs 2015, 13, 3479-3513. [CrossRef] [PubMed]

11. Larrosa, I.; Da Silva, M.I.; Gómez, P.M.; Hannen, P.; Ko, E.; Lenger, S.R.; White, A.J.P.; Wilton, D.; Barrett, A.G.M. Highly convergent three component benzyne coupling: The total synthesis of ent-clavilactone B. J. Am. Chem. Soc. 2006, 128, 14042-14043. [CrossRef] [PubMed]

12. Takao, K.; Mori, K.; Kasuga, K.; Nanamiya, R.; Namba, A.; Fukushima, Y.; Nemoto, R.; Mogi, T.; Yasui, H.; Ogura, A.; et al. Total Synthesis of Clavilactones. J. Org. Chem. 2018, 83, 7060-7075. [CrossRef] [PubMed]

13. Arnone, A.; Cardillo, R.; Meille, S.V.; Nasini, G.; Tolazz, M. Secondary mould metabolites. Part 47. isolation and structure elucidation of clavilactones A-C, new metabolites from the fungus Clitocybe clavipes. J. Chem. Soc. Perkin Trans. 1 1994, 2165-2168. [CrossRef]

14. Merlini, L.; Nasini, G.; Scaglioni, L.; Cassinelli, G.; Lanzi, C. Structure elucidation of clavilactone D: An inhibitor of protein tyrosine kinases. Phytochemistry 2000, 53, 1039-1041. [CrossRef]

15. Kawagishi, H.; Miyazawa, T.; Kume, H.; Arimoto, Y.; Inakuma, T. Aldehyde dehydrogenase inhibitors from the mushroom Clitocybe clavipes. J. Nat. Prod. 2002, 65, 1712-1714. [CrossRef] [PubMed]

16. Cassinelli, G.; Lanzi, C.; Pensa, T.; Gambetta, R.A.; Nasini, G.; Cuccuru, G.; Cassinis, M.; Pratesi, G.; Polizzi, D.; Tortoreto, M.; et al. Clavilactones, a novel class of tyrosine kinase inhibitors of fungal origin. Biochem. Pharmacol. 2000, 59, 1539-1547. [CrossRef]

17. Sun, Z.; Zhu, N.; Zhou, M.; Huo, X.; Wu, H.; Tian, Y.; Yang, J.; Ma, G.; Yang, Y.L.; Xu, X. Clavipines A-C, antiproliferative meroterpenoids with a fused azepine skeleton from the basidiomycete Clitocybe clavipes. Org. Chem. Front. 2019. [CrossRef] 
18. Yao, X.S.; Ebizuka, Y.; Noguchi, H.; Kiuchi, F.; Shibuya, M.; Iitaka, Y.; Seto, H.; Ushio, S. Biologically active constituents of arnebia euchroma: Structure of arnebinol, an ansa-type monoterpenylbenzenoid with inhibitory activity on prostaglandin biosynthesis. Chem. Pharm. Bull. 1991, 39, 2956-2961. [CrossRef] [PubMed]

19. Chen, J.J.; Hung, H.C.; Sung, P.J.; Chen, I.S.; Kuo, W.L. Aporphine alkaloids and cytotoxic lignans from the roots of Illigera luzonensis. Phytochemistry 2011, 72, 523-532. [CrossRef] [PubMed]

20. Yin, X.; Feng, T.; Li, Z.H.; Dong, Z.J.; Li, Y.; Liu, J. Highly oxygenated meroterpenoids from fruiting bodies of the mushroom Tricholoma terreum. J. Nat. Prod. 2013, 76, 1365-1368. [CrossRef] [PubMed]

Sample Availability: Samples of the compounds (1-5) are not available from the authors.

(C) 2019 by the authors. Licensee MDPI, Basel, Switzerland. This article is an open access article distributed under the terms and conditions of the Creative Commons Attribution (CC BY) license (http://creativecommons.org/licenses/by/4.0/). 